\title{
ẢNH HƯỞNG CỦA KHẢ NĂNG ĐÁP ÚNG CHUỖI CUNG ÚNG ĐẾN NĂNG LỰC CẠNH TRANH DOANH NGHIẸP, NGHIÊN CỬU TRƯỜnG HỢP TẠI TỈNH BÀ RỊA VŨNG TÀU
}

\author{
NGUYẼ̃N THÀNH LONG, PHẠM XUÂN GIANG \\ Truờng Đại học Công nghiệp thành phố Hồ Chí Minh; \\ nguyenthanhlong@iuh.edu.vn,phamxuangiang@iuh.edu.vn
}

Tóm tắt. Nghiên cứu này nhằm xác định các yếu tố tạo ra khả năng đáp ứng của chuỗi cung ứng ảnh hưởng đến năng lực cạnh tranh của doanh nghiệp, nghiên cứu trường hợp các doanh nghiệp sản xuất công nghiệp tỉnh Bà Rịa Vũng Tàu. Kết quả nghiên cứu cho thấy, có 4 yếu tố tạo ra khả năng đáp ứng của chuỗi cung ứng ảnh hưởng đến năng lực cạnh tranh (NLCT) của doanh nghiệp sản xuất công nghiệp tỉnh Bà Rịa Vũng Tàu, cụ thể: Thứ nhất, khả năng đáp ứng của hệ thống vận hành. Thứ hai, khả năng đáp ứng của quá trình hậu cần. Thứ ba, khả năng đáp ứng của mạng lưới các nhà cung cấp. Thứ tư, khả năng cộng tác với nhà cung cấp chiến lược. Từ kết quả này, nghiên cứu đưa ra một số hàm ý quản trị về khả năng đáp ứng của chuỗi cung ứng cho doanh nghiệp sản xuất công nghiệp tỉnh Bà Rịa Vũng Tàu trong thời gian tới nhằm giúp các doanh nghiệp này nâng cao NLCT và phát triển bền vững.

Từ khóa. Khả năng đáp ứng chuỗi cung ứng, doanh nghiệp sản xuất công nghiệp, năng lực cạnh tranh của doanh nghiệp.

\section{THE INFLUENCE OF BUSINESS SUPPLY CHAIN RESPONSIVENESS TO COMPETITIVENESS - A CASE STUDY OF BUSINESS IN BA RIA VUNG TAU PROVINCE}

\begin{abstract}
This study aims to identify factors creating responsiveness of the supply chain influencing the business competitiveness, applied for manufacturing businesses in Ba Ria Vung Tau. The reults reveal four factors contributing to supply chain responsiveness which impact the competitiveness of businesses: (1) the responsiveness of operating systems, (2) the responsivess of logistics process, (3) the responsivess of suppliers, and (4) the ability of co-operation with strategic suppliers. Based on the findings, managerial implications of the responsiveness of business supply chain for manufacturing businesses in Ba Ria Vung Tau in coming time are proposed to enhance their competitiveness and sustainable development.
\end{abstract}

Keywords. responsiveness of the supply chain, manufacturing businesses, business competitiveness.

\section{1. ĐẶT VẤN ĐỀ}

Trong bối cảnh hội nhập hiện nay, 90\% các CEO trên thế giới đều đặt quản trị chuỗi cung ứng lên hàng đầu bởi việc cạnh tranh trên thị trường ngày càng tăng cao, giá bán trên thị trường và giá thu mua nguồn cung cấp hàng hóa ngày càng bị siết chặt. Hoạt động chuỗi cung ứng có hiệu quả sẽ giúp doanh nghiệp chiếm lĩnh thị phần và sự tín nhiệm của khách hàng, tạo nên giá trị cho cổ đông và nâng cao NLCT cho doanh nghiệp trên thị trường. Theo thống kê những năm gần đây, nhờ có chuỗi cung ứng hiệu quả, các tập đoàn quốc tế lớn như Dell, Wal-Mart đã đạt lợi nhuận cao hơn từ 4-6\% so với đối thủ. Một nghiên cứu độc lập cũng cho thấy một vài công ty hàng đầu trên thế giới như Apple, Coca-cola, Samsung đã tận dụng hiệu quả chuỗi cung ứng của họ để vươn cao trong môi trường cạnh tranh, đạt được mức tăng giá trị công ty cao hơn $40 \%$ so với các đối thủ khác. Ngoài ra, các nghiên cứu cũng đã chỉ ra rằng quản lý chuỗi cung ứng hiệu quả có thể mang lại chi phí cho chuỗi cung ứng giảm từ 25-50\%; lượng hàng tồn kho giảm từ 25-60\%; độ chính xác trong việc dự báo sản xuất tăng từ 25-80\%; cải thiện vòng cung ứng đơn hàng lên 30-50\%; tăng lợi nhuận sau thuế lên đến 20\%. Việt Nam cũng được xem là một trong những quốc gia có nền kinh tế đang phát triển mạnh với GDP năm 2016 tăng 6,21\%. Tuy nhiên, các doanh nghiệp Việt Nam đang phải đối mặt với nhiều khó khăn, hạn chế trong quá trình hội nhập bởi hơn $90 \%$ trong số này là các doanh nghiệp nhỏ và vừa. Các doanh nghiệp này phải cạnh tranh quyết liệt từ những yếu tố đầu vào đến quá trình phân phối sản phẩm đầu ra, nhằm chinh phục khách hàng và chiếm lĩnh thị 
phần. Trong quá trình đó, khả năng đáp ứng của chuỗi cung ứng là một trong những yếu tố quyết định sự tồn tại, phát triển ảnh hưởng đến NLCT của doanh nghiệp.

Bà Rịa - Vũng Tàu là một tỉnh thuộc miền Đông Nam bộ với vị trí địa lý đặc biệt thuận lợi thuộc vùng kinh tế trọng điểm phía Nam, cửa ngõ tiểu vùng sông Mê Kông, có lợi thế về cảng nước sâu và phát triển các khu công nghiệp. Theo Cục Thống kê Bà Rịa - Vũng Tàu năm 2016 toàn tỉnh có hơn 6.800 doanh nghiệp với tổng doanh thu thuần 487,695 ngàn tỷ đồng. Trong đó, sản xuất nông nghiệp, lâm nghiệp và thủy sản là 70 doanh nghiệp với doanh thu thuần 952,7 tỷ đồng chiếm tỷ lệ $0,2 \%$; khai khoáng là 198 doanh nghiệp với doanh thu thuần 122,7 ngàn tỷ đồng chiếm tỷ lệ $25,18 \%$; sản xuất công nghiệp (chế biến, chế tạo) là 1.205 doanh nghiệp với doanh thu thuần 167,42 ngàn tỷ đồng chiếm tỷ lệ 34,33\%; sản xuất và phân phối điện, khí đốt, nước nóng là 47 doanh nghiệp với doanh thu thuần 52,19 ngàn tỷ đồng chiếm tỷ lệ $10,7 \%$; xây dựng là 957 doanh nghiệp với doanh thu thuần 16,1 ngàn tỷ đồng chiếm tỷ lệ $3,3 \%$; thương mại và sửa chữa là 2.404 doanh nghiệp với doanh thu thuần 91,32 ngàn tỷ đồng chiếm tỷ lệ $18,73 \%$; vận tải và kho bãi là 410 doanh nghiệp với doanh thu thuần 21,35 ngàn tỷ đồng chiếm tỷ lệ $3,2 \%$; dịch vụ và các hoạt đông khác là 1.509 doanh nghiệp với doanh thu thuần 15,59 ngàn tỷ đồng chiếm tỷ lệ 4,38\%. Với số lượng 1.205 doanh nghiệp, doanh thu thuần chiếm tỷ lệ $34,33 \%$, các doanh nghiệp sản xuất công nghiệp (chế biến, chế tạo) đóng vai trò quan trọng đối với sự phát triển kinh tế - xã hội của địa phương. Để việc sản xuất ổn định, đảm bảo chất lượng sản phẩm, đáp ứng tốt nhu cầu của khách hàng, doanh nghiệp rất cần có khả năng đáp ứng tốt của chuỗi cung ứng. Vì vậy, nghiên cứu các yếu tố tạo ra khả năng đáp ứng của chuỗi cung ứng ảnh hưởng đến NLCT của các doanh nghiệp sản xuất công nghiệp tỉnh Bà Rịa Vũng Tàu là cần thiết.

\section{CƠ SỞ LÝ THUYẾT VÀ MÔ HÌNH NGHIÊN CỨU}

\subsection{Cơ sở lý thuyết}

\subsubsection{Khả năng đáp ứng của chuỗi cung ứng}

Khả năng đáp ứng của chuỗi cung ứng là khả năng phản ứng đúng mức độ và thời gian trước những thay đổi trong nhu cầu của khách hàng (Holweg, 2005 [15]; Duclos, Vokurka \& Lummus 2003 [9]). Theo Aquilano, Chase và Davis (1995) [1] chi phí thấp, chất lượng cao và cải thiện sự đáp ứng trong dịch vụ khách hàng là chìa khóa chính để cạnh tranh trong giai đoạn hiện nay. Bowersox, Closs và Stank (1999) [4] cho rằng, doanh nghiệp cần phải phản ứng nhanh với những tình huống bất lợi, không chắc chắn ngày càng tăng cao. Những bất lợi đó sẽ ảnh hưởng lớn đến khả năng đáp ứng của chuỗi cung ứng nói riêng và hiệu quả hoạt động của doanh nghiệp nói chung. Vì vậy, việc xây dựng khả năng đáp ứng của chuỗi cung ứng được cho là hết sức quan trọng, bao gồm các yếu tố:

- Khả năng đáp ứng của hệ thống vận hành: là khả năng đáp ứng tốt của hoạt động sản xuất và dịch vụ trong doanh nghiệp để giải quyết kịp thời những thay đổi trong nhu cầu của khách hàng. Theo Duclos và cộng sự (2003) [9] khả năng đáp ứng của hệ thống vận hành tại những điểm trọng yếu trong hoạt động sản xuất và dịch vụ là một phần không thể thiếu trong chuỗi cung ứng. Các tác giả cũng cho rằng, để đáp ứng tốt nhu cầu của khách hàng tiêu dùng cuối cùng, mỗi thực thể trong hệ thống vận hành phải đảm bảo cung cấp sản phẩm, dịch vụ kịp thời và đáng tin cậy.

- Khả năng đáp ứng của quá trình hậu cần: là khả năng đáp ứng của hoạt động vận chuyển, phân phối và hệ thống kho bãi để giải quyết kịp thời những thay đổi trong nhu cầu của khách hàng. Theo Fawcett (1992) [11] khả năng đáp ứng của hoạt động hậu cần là một phần quan trọng tạo nên sự thành công của chiến lược cung ứng trong doanh nghiệp.

- Khả năng đáp ứng của mạng lưới các nhà cung cấp: là năng lực của các nhà cung cấp chính cho doanh nghiệp để giải quyết kịp thời những thay đổi trong nhu cầu của khách hàng. Theo Christopher và Peck (2004) [6] bí quyết thành công của chuỗi cung ứng là khả năng đáp ứng và sự linh hoạt của mạng lưới các nhà cung cấp, bao gồm cả nhà cung cấp trực tiếp và gián tiếp. Doanh nghiệp có khả năng đáp ứng nhanh được những thay đổi trong nhu cầu của khách hàng phụ thuộc rất nhiều vào năng lực của các nhà cung cấp.Theo Walker (2005) [29] nguyên nhân dẫn đến rủi ro trong sản xuất, giảm năng suất sử dụng công nghệ, máy móc, thiết bị hay giảm khả năng cạnh tranh của doanh nghiệp là do sự bất cập của mạng lưới các nhà cung cấp. Vì vậy, doanh nghiệp cần phải có mạng lưới các nhà cung cấp tốt, luôn sẵn sàng phản ứng lại với bất kỳ hiệu ứng gợn sóng nào trên thị trường. 
- Khả năng cộng tác với nhà cung cấp chiến lược chính là các mối quan hệ lâu dài, bền vững giữa doanh nghiệp và các nhà cung cấp chiến lược. Theo Li và cộng sự (2006) [17], khả năng cộng tác với nhà cung cấp chiến lược phải được xây dựng, thúc đẩy và tham gia bởi những cá nhân của từng doanh nghiệp nhằm duy trì lợi ích giữa các bên. Tan, Lyman và Wisner (2002) [27] cho rằng, nhà cung cấp chiến lược có thể tham gia vào quá trình thiết kế ra sản phẩm, hỗ trợ việc lựa chọn nguồn nguyên vật liệu và công nghệ tốt hơn, hỗ trợ tiêu thụ và đánh giá chất lượng sản phẩm trên thị trường. Theo Stuart (1993) [26], thông qua mối quan hệ chặt chẽ với nhà cung cấp chiến lược, chuỗi cung ứng của doanh nghiệp luôn sẵn sàng ứng phó với những biến động của môi trường, được chia sẽ những rủi ro cũng như hưởng được những lợi ích từ mối quan hệ lâu dài và bền vững này.

\subsubsection{Năng lục cạnh tranh của doanh nghiệp}

Theo Aldington Report (1985) doanh nghiệp có khả năng cạnh tranh là doanh nghiệp có thể sản xuất sản phẩm, dịch vụ với chất lượng vượt trội, giá cả thấp hơn đối thủ cạnh tranh trong và ngoài nước. Khả năng cạnh tranh đồng nghĩa với việc đạt được lợi ích lâu dài của doanh nghiệp, khả năng đảm bảo thu nhập cho người lao động và chủ doanh nghiệp. Porter (1980) [22] cho rằng năng suất lao động là thước đo duy nhất về NLCT. NLCT là khả năng tạo dựng, duy trì, sử dụng và sáng tạo mới các lợi thế cạnh tranh của doanh nghiệp, để tạo ra năng suất và chất lượng cao hơn đối thủ, chiếm lĩnh thị phần lớn, tạo ra thu nhập cao và phát triển bền vững. Theo Porter (1980) [22] nếu một công ty chỉ tập trung vào hai mục tiêu tăng trưởng và đa dạng hóa sản phẩm thì không đảm bảo cho sự thành công lâu dài. Điều quan trọng nhất đối với bất kỳ một công ty nào là xây dựng được một lợi thế cạnh tranh bền vững. Tâm điểm trong lý thuyết cạnh tranh của Michael Porter là việc đề xuất mô hình 5 áp lực. Ông cho rằng trong bất kỳ ngành nghề kinh doanh nào cũng có 5 yếu tố tác động, đó là: (1) Sự cạnh tranh giữa các công ty đang tồn tại; (2) Mối đe dọa về việc một đối thủ mới tham gia vào thị trường; (3) Nguy cơ có các sản phẩm thay thể xuất hiện; (4) Vai trò của các công ty bán lẻ; (5) Nhà cung cấp đầy quyền lực.

Theo D'Cruz (1992) [7], NLCT cấp độ doanh nghiệp có thể được định nghĩa là khả năng thiết kế, sản xuất và tiếp thị sản phẩm hoặc vượt trội so với cùng những thứ đó mà được cung cấp bởi đối thủ cạnh tranh, xem xét cả chất lượng về giá và phi giá cả. Còn Horstmann và Markusen (1992) [16] cho rằng, một nhà sản xuất là cạnh tranh nếu như nó có một mức chi phí đơn vị trung bình bằng hoặc thấp hơn chi phí đơn vị của các nhà cạnh tranh quốc tế. Còn theo Dunning (1993) [10], NLCT là khả năng cung ứng sản phẩm của chính doanh nghiệp trên các thị trường khác nhau mà không phân biệt nơi bố trí của doanh nghiệp đó. NLCT của doanh nghiệp chính là khả năng doanh nghiệp có thể sản xuất sản phẩm với chi phí biến đổi trung bình thấp hơn giá của nó trên thị trường, có nghĩa là doanh nghiệp nào có khả năng sản xuất ra sản phẩm có chất lượng tương tự như sản phẩm của doanh nghiệp khác, nhưng với chi phí thấp hơn thì được coi là có khả năng cạnh tranh cao. Theo tác giả Nguyễn Bách Khoa (2004) [19], NLCT của doanh nghiệp được hiểu là tích hợp các khả năng, nguồn nội lực để duy trì và phát triển thị phần, lợi nhuận và định vị những ưu thế cạnh tranh của doanh nghiệp đó trong mối quan hệ với đối thủ cạnh tranh trực tiếp, đối thủ tiềm tàng trên một thị trường mục tiêu xác định.

Tóm lại, NLCT của doanh nghiệp không phải là khái niệm một chiều, thay vào đó phải có nhiều yếu tố được xem xét. Theo các tác giả Wint (2003) [31]; Barclay (2005) [3] và Williams (2007) [30], để xác định được những yếu tố này là rất quan trọng và thông qua các yếu tố này doanh nghiệp có thể cải thiện khả năng cạnh tranh của mình. Các tác giả cho rằng, những yếu tố tạo ra sự cải thiện NLCT của doanh nghiệp bao gồm: sự đổi mới, các tiêu chuẩn quốc tế, khả năng lãnh đạo, tập trung chất lượng, đáp ứng cạnh tranh.

\subsubsection{Anh hưởng của chuỗi giá trị đến năng lục cạnh tranh của doanh nghiệp}

Theo hệ thống chuỗi giá trị của Porter (1985) [23], chuỗi giá trị là một khái niệm được đưa ra đầu tiên bởi Porter vào năm 1985 trong cuốn "Competitive Advantage: Creating and Sustaining Superior Performance". Theo sách này, chuỗi giá trị được định nghĩa là: "Tổng thể các hoạt động liên quan đến sản xuất và tiêu thụ một sản phẩm hoặc dịch vụ nào đó. Trong chuỗi giá trị diễn ra quá trình tương tác giữa các yếu tố cần và đủ để tạo ra một hoặc một nhóm sản phẩm và các hoạt động phân phối, tiêu thụ sản phẩm, nhóm sản phẩm đó theo một phương thức nhất định. Giá trị tạo ra của chuỗi bao gồm tổng các giá trị tạo ra tại mỗi công đoạn của chuỗi”". 


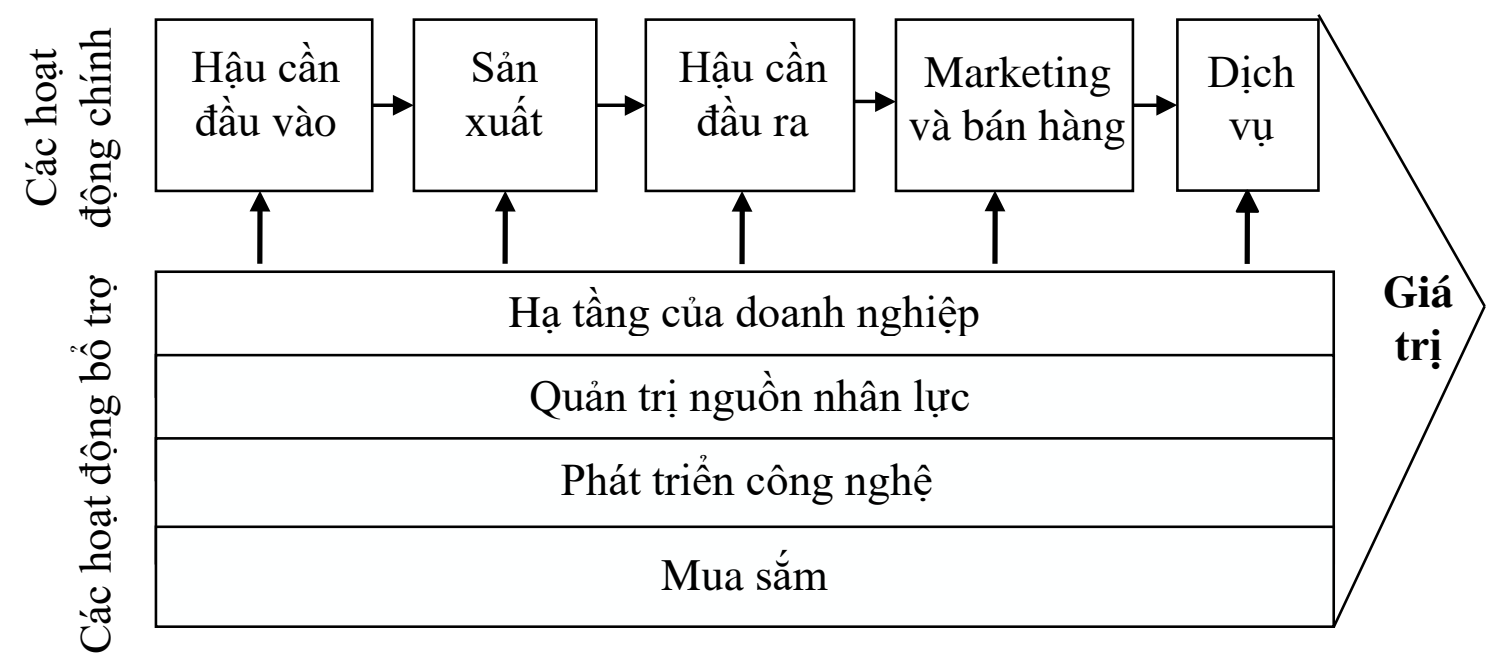

Hình 2.1 Chuỗi giá trị của một doanh nghiệp Nguồn: Porter (1985)

Porter (1985) cho rằng chuỗi giá trị gồm có 9 hoạt động, trong đó có 5 hoạt động cơ bản và 4 hoạt động bổ trợ:

Những hoạt động cơ bản thể hiện một chuỗi những công việc từ cung cấp nguyên vật liệu đầu vào, gia công sản phẩm, phân phối sản phẩm, đến hoạt động bán hàng và các dịch vụ sau bán hàng. Các hoạt động cơ bản này trực tiếp liên quan đến hoạt động chuỗi cung ứng trong doanh nghiệp, nó tạo ra giá trị sử dụng của sản phẩm và đưa sản phẩm đến với người sử dụng. Hoạt động hậu cần đầu vào liên quan đến việc tiếp nhận, lưu kho và đảm bảo nguyên vật liệu cho sản xuất. Hoạt động sản xuất liên quan đến quá trình "chế biến" nguyên vật liệu thành sản phẩm cuối cùng. Hoạt động hậu cần đầu ra liên quan đến tiếp nhận, lưu kho và phân phối thành phẩm đến nơi tiêu thụ. Hoạt động marketing và bán hàng liên quan đến việc tạo ra những phương thức và khuyến khích người mua. Dịch vụ (sau bán hàng) liên quan đến các hoạt động nhằm duy trì hoặc tăng cường giá trị của sản phẩm. Vì vậy, đây có thể coi là các hoạt động trực tiếp ảnh hưởng đến NLCT của doanh nghiệp, làm tốt các hoạt động cơ bản này cũng đồng nghĩa sẽ tạo ra NLCT vượt trội so với đối thủ.

Những hoạt động bổ trợ, tuy không trực tiếp liên quan đến việc tạo ra giá trị sử dụng cho sản phẩm, nhưng chúng tham gia vào toàn bộ quá trình tạo ra giá trị của các hoạt động cơ bản, có chức năng trợ giúp cho các hoạt động cơ bản. Hoạt động quản trị thu mua, kiểm soát sự lưu chuyển vật tư qua chuỗi giá trị từ cung cấp đến sản xuất và đi vào phân phối, chúng góp phần kiểm soát chất lượng đầu vào trong quá trình sản xuất, đồng thời hiệu quả của các hoạt động này có thể làm giảm chi phí sản xuất của doanh nghiệp. Hoạt động nghiên cứu và phát triển $(\mathrm{R} \& \mathrm{D})$ liên quan đến việc phát triển các sản phẩm mới và các phương pháp công nghệ mới, cho phép giảm chi phí sản xuất hoặc tạo ra những sản phẩm hấp dẫn hơn có thể bán ở mức giá cao hơn. Hoạt động quản trị nguồn nhân lực đảm bảo rằng công ty sử dụng hợp lý những người có kỹ năng để thực hiện có hiệu quả các hoạt động tạo ra giá trị. Hạ tầng (quản lý) của doanh nghiệp là hoạt động bổ trợ có một đặc trưng khác so với các hoạt động khác. Hạ tầng của doanh nghiệp là khung quản lý chung của toàn doanh nghiệp, trong đó bao gồm cơ cấu tổ chức, các hệ thống kiểm soát và văn hóa doanh nghiệp. Vì vậy, có thể coi đây là các hoạt động có ảnh hưởng đến NLCT của doanh nghiệp.

Vokurka, Zank và Lund (2002) [28] cho rằng, khả năng cạnh tranh của doanh nghiệp được cải thiện thông qua hiệu quả của chuỗi cung ứng. Theo các tác giả này, hoạt động cốt lõi của quản trị chuỗi cung ứng là tập trung vào việc cung cấp đúng sản phẩm, đúng thời điểm trong từng giai đoạn của dây chuyền cung ứng nhằm đảm bảo yêu cầu về chất lượng, độ tin cậy và khả năng thích ứng của sản phẩm trên thị trường. Còn theo Somuyiwa và Adebayo, Toyin (2012), quản lý chuỗi cung ứng là quản lý dòng nguyên vật liệu, vốn, hệ thống thông tin một cách hiệu quả nhằm tối đa hóa sự hài lòng của khách hàng, nó có mối quan hệ chặt chẽ với NLCT của doanh nghiệp trên thị trường. Nghiên cứu tiến hành khảo sát 115 công ty sản xuất công nghiệp, kết quả khảo sát được phân tích hồi qui đa biến. Kết quả phân tích hồi qui 
cho thấy, có mối quan hệ chặt chẽ giữa khả năng đáp ứng chuỗi cung ứng, quản trị chuỗi cung ứng và NLCT của doanh nghiệp.

\subsection{Mô hình nghiên cứu}

Trên cơ sở tiếp cận nghiên cứu của Vokurka, Zank và Lund (2002) [28]; Somuyiwa và Adebayo, Toyin (2012) [24] tác giả đưa ra các thuộc tính nhằm xây dựng dàn bài phỏng vấn chuyên gia và thảo luận nhóm. Tổng hợp các ý kiến của chuyên gia và ý kiến tại cuộc thảo luận nhóm cho thấy, đa số ý kiến đều đồng tình với các yếu tố tạo ra khả năng đáp ứng của chuỗi cung ứng ảnh hưởng đến NLCT của doanh nghiệp, nghiên cứu trường hợp các doanh nghiệp sản xuất công nghiệp tỉnh Bà Rịa Vũng Tàu. Tuy nhiên, theo các chuyên gia, để phù hợp với điều kiện đặc thù của địa phương và thuận tiện cho việc khảo sát, nghiên cứu nên bổ sung thêm khả năng công tác với nhà cung cấp chiến lược vào mô hình. Do đó, mô hình đề xuất cho nghiên cứu như sau:

Khả năng đáp ứng của hệ thống vận hành

Hình 2.1: Mô hình nghiên cứu

\section{Trên cơ sở đó các giả thuyết như sau:}

$\mathrm{H}_{1}$ : Khả năng đáp ứng của hệ thống vận hành; $\mathrm{H}_{2}$ : Khả năng đáp ứng của quá trình hậu cần; $\mathrm{H}_{3}$ : Khả năng đáp ứng của mang lưới các nhà cung cấp; $\mathrm{H}_{4}$ : Khả năng cộng tác với nhà cung cấp chiến lược đều có ảnh hưởng cùng chiều $(+)$ đến NLCT của doanh nghiệp sản xuất công nghiệp tỉnh Bà Rịa Vũng Tàu. Dựa trên mô hình nghiên cứu và các giả thuyết nghiên cứu, tác giả tiến hành hoàn thiện bộ thang đo cho các yếu tố trong mô hình, chi tiết theo bảng 2.1. 
Bảng 2.1: Tổng hợp thang đo

\begin{tabular}{|c|c|c|}
\hline Yế & Mã hóa & Biến quan sát và tác giả \\
\hline \multirow{5}{*}{$\begin{array}{l}\text { Khả năng } \\
\text { đáp ứng của } \\
\text { hệ thống } \\
\text { vận hành }\end{array}$} & HT1 & $\begin{array}{l}\text { Hệ thống vận hành trong doanh nghiệp rất linh hoạt để đáp ứng tốt những thay đổi trong } \\
\text { nhu cầu của khách hàng [9]; [15]; [24]. }\end{array}$ \\
\hline & HT2 & Các giai đoạn trong hệ thống vận hành có sự phối hợp nhịp nhàng, linh hoạt [9]; [15]; [24]. \\
\hline & HT3 & $\begin{array}{l}\text { Mỗi giai đoạn trong hệ thống vận hành luôn đảm bảo chất lượng sản phẩm, đảm bảo đầu } \\
\text { vào đáng tin cậy cho giai đoạn sau [9]; [15]; [24]; [28]. }\end{array}$ \\
\hline & HT4 & Hệ thống vận hành trong doanh nghiệp luôn đảm bảo tiến độ [9]; [15]; [24]; [28]. \\
\hline & HT5 & Hệ thống vận hành trong doanh nghiệp luôn đảm bảo chất lượng với khách hàng [9]; [24]. \\
\hline \multirow{6}{*}{$\begin{array}{l}\text { Khả năng } \\
\text { đáp ứng của } \\
\text { quá trình } \\
\text { hậu cần }\end{array}$} & QT1 & $\begin{array}{l}\text { Hàng hóa, nguyên vật liệu được vận chuyển đến kho đúng tiến độ [9]; [11]; [15]; [24]; } \\
\text { [28]. }\end{array}$ \\
\hline & QT2 & $\begin{array}{l}\text { Thông tin về hàng hóa, nguyên vật liệu nhập kho luôn rõ ràng, đúng lúc [9]; [11]; [15]; } \\
{[24] ;[28] \text {. }}\end{array}$ \\
\hline & QT3 & $\begin{array}{l}\text { Sự phối hợp giữa doanh nghiệp và nhà cung cấp rất nhịp nhàng, linh hoạt [9]; [11]; [15]; } \\
\text { [24]; [28]. }\end{array}$ \\
\hline & QT4 & $\begin{array}{l}\text { Hệ thống kho bãi của doanh nghiệp đảm bảo yêu cầu phục vụ tốt cho hệ thống vận hành } \\
\text { [9]; [11]; [15]; [24]; [28]. }\end{array}$ \\
\hline & QT5 & $\begin{array}{l}\text { Các hoạt động xuất, nhập nguyên vật liệu của hệ thống kho nhanh gọn và đơn giản [9]; } \\
{[11] ;[15] ;[24] ;[28] \text {. }}\end{array}$ \\
\hline & QT6 & $\begin{array}{l}\text { Nguyên vật liệu trong kho luôn được kiểm tra, bảo quản đúng qui trình, đảm bảo chất } \\
\text { lương [11]; [24]. }\end{array}$ \\
\hline \multirow{5}{*}{$\begin{array}{l}\text { Khả năng } \\
\text { đáp ứng của } \\
\text { mạng lưới } \\
\text { các nhà } \\
\text { cung cấp }\end{array}$} & ML1 & $\begin{array}{l}\text { Doanh nghiệp có mạng lưới nhà cung cấp đảm bảo uy tín và tính ổn định cao [6]; [24]; } \\
\text { [29]. }\end{array}$ \\
\hline & ML2 & $\begin{array}{l}\text { Mạng lưới nhà cung cấp rất linh hoạt, đáp ứng kịp thời những thay đổi của doanh nghiệp } \\
\text { [6]; [24]; [29]. }\end{array}$ \\
\hline & ML3 & $\begin{array}{l}\text { Năng lực cung cấp nguyên liệu của các nhà cung cấp trong mạng lưới luôn đạt hiệu quả } \\
\text { cao [6]; [24]; [29]. }\end{array}$ \\
\hline & ML4 & của các nhà cung cấp tốt [6]; [24]; [29]. \\
\hline & ML5 & cấp tốt [6]; [24] \\
\hline \multirow{5}{*}{$\begin{array}{l}\text { Khả năng } \\
\text { cộng tác với } \\
\text { nhà cung } \\
\text { cấp chiến } \\
\text { lược }\end{array}$} & CT1 & $\begin{array}{l}\text { Doanh nghiệp coi trọng việc xây dựng mối quan hệ bền vững, lâu dài với nhà cung cấp } \\
\text { [18]; [24]; [26]; [27]. }\end{array}$ \\
\hline & $\mathrm{CT} 2$ & $\begin{array}{l}\text { Doanh nghiệp luôn có chiến lược mở rộng và phát triển nhà cung cấp tiềm năng [18]; [24]; } \\
\text { [26]; [27]. }\end{array}$ \\
\hline & CT3 & $\begin{array}{l}\text { Doanh nghiệp luôn xem nhà cung cấp là đối tác chiến lược cho sự phát triển [18]; [24]; } \\
\text { [26]; [27]. }\end{array}$ \\
\hline & CT4 & $\begin{array}{l}\text { Mối quan hệ giữa doanh nghiệp và nhà cung cấp hiện tại rất tin cậy, bền vững [18]; [24]; } \\
{[26] ;[27] \text {. }}\end{array}$ \\
\hline & CT5 & $\begin{array}{l}\text { Lãnh đạo trong doanh nghiệp không có sự phân biệt đối xử giữa nhà cung cấp và khách } \\
\text { hàng [18]; [24]; [26]; [27]. }\end{array}$ \\
\hline \multirow{4}{*}{$\begin{array}{c}\text { Năng lực } \\
\text { cạnh tranh } \\
\text { của doanh } \\
\text { nghiệp tỉnh } \\
\text { Bà Rịa } \\
\text { Vũng Tàu }\end{array}$} & NLCT1 & $\begin{array}{l}\text { Hiệu quả NLCT của doanh nghiệp làm gia tăng khả năng mở rộng và phát triển thị phần } \\
\text { [8]; [14]; [17]. }\end{array}$ \\
\hline & NLCT2 & $\begin{array}{l}\text { Hiệu quả NLCT của doanh nghiệp làm gia tăng vị trí, hình ảnh trên thị trường [8]; [14]; } \\
\text { [17]. }\end{array}$ \\
\hline & NLCT3 & $\begin{array}{l}\text { Hiệu quả NLCT của doanh nghiệp làm gia tăng hiệu quả về mặt tài chính [18]; [8]; [14]; } \\
\text { [17]; [22]. }\end{array}$ \\
\hline & NLCT4 & $\begin{array}{l}\text { Hiệu quả NLCT của doanh nghiệp làm gia tăng sự ổn định và phát triển bền vững trong } \\
\text { tương lai (Tổng hợp ý kiến chuên gia) [8]; [14]; [17]. }\end{array}$ \\
\hline
\end{tabular}




\section{PHƯƠNG PHÁP NGHIÊN CÚU}

Nghiên cứu này được thực hiện thông qua 3 giai đoạn:

Giai đoạn 1, nội dung giai đoạn này tác giả sử dụng phương pháp chuyên gia, trên cơ sở tham khảo ý kiến chuyên gia và thảo luận nhóm nhằm hoàn thiện thang đo và thiết kế bảng câu hỏi điều tra.

Giai đoạn 2, nội dung giai đoạn này sẽ thực hiện: Kiểm định độ tin cậy của thang đo với hệ số Cronbach's Alpha và phân tích nhân tố khám phá. Theo Hair và công sự (2006) [12] kích thước mẫu tối thiểu phải $\geq \mathrm{m} \times 5$, trong đó $\mathrm{m}$ là số lượng biến quan sát. Vậy, với 25 biến quan sát trong nghiên cứu này kích thước mẫu tối thiểu phải $\geq 125$. Tuy nhiên, để đảm bảo độ tin cậy cao tác giả tiến hành khảo sát 145 đối tượng là các giám đốc, phó giám đốc hoặc người được giám đốc ủy quyền tham gia nhiệm vụ lãnh đạo, quản lý và điều hành doanh nghiệp, có kinh nghiệm làm việc và hiểu tình hình kinh doanh của doanh nghiệp. Tất cả số liệu thu thập từ bảng câu hỏi điều tra được mã hóa, xử lý bằng phần mềm SPSS và AMOS. Theo Nunnally và Bernstein (1994) [21], những biến quan sát nào có hệ số tương quan biến tổng lớn hơn 0,3 và có hệ số Cronbach's Alpha lớn hơn 0,7 thì mới đảm bảo độ tin cậy của thang đo. Mục đích của phân tích nhân tố khám phá để thu nhỏ và tóm tắt các dữ liệu. Phương pháp này dựa vào tỷ số rút trích nhân tố (Eigenvalue), phân tích nhân tố là thích hợp và các biến quan sát trong tổng thể có mối tương quan với nhau khi tồng phương sai trích phải $>50 \%$, hệ số $\mathrm{KMO}$ nằm trong khoảng 0,5 đến 1 , hệ số Sig. $\leq 5 \%$, các Factor loading của tất cả các biến quan sát đều $>0,5$; chênh lệch trọng số $\lambda \mathrm{iA}-\lambda \mathrm{iB}$ đều $>$ 0,3 (Nguyễn Đình Thọ, 2011) [20].

Giai đoạn 3, hai nội dung trong giai đoạn này, (1) phân tích nhân tố khẳng định $\mathrm{CFA}$ và (2) Kiểm định mô hình nghiên cứu bằng phân tích mô hình cấu trúc tuyến tính SEM (Structural Equation Modeling). Mục đích của phân tích nhân tố khẳng định CFA giúp làm sáng tỏ: (1) Tính đơn hướng; (2) Độ tin cậy của thang đo; (3) Giá trị hội tụ; (4) Giá trị phân biệt. Theo Steenkamp và Van Trijp (1991) [25]; Hair và cộng sự (1998) [13], một mô hình nghiên cứu được xem là phù hợp với dữ liệu thị trường nếu kiểm định Chi-quare có giá trị $\mathrm{P}$-value $<5 \% ; \mathrm{CMIN} / \mathrm{df} \leq 2$, một số trường hợp $\mathrm{CMIN} / \mathrm{df}$ có thể $\leq 3$ (Carmines và McIver, 1981); GFI, TLI, CFI $\geq 0,9$. Tuy nhiên, theo quan điểm gần đây của các nhà nghiên cứu thì GFI vẫn có thể chấp nhận được khi lớn hơn 0,$8 ;$ RMSEA $\leq 0,08$. Ngoài những chỉ tiêu trên, kết quả kiểm định cũng phải đảm bảo độ tin cậy tổng hợp $>0,6$; phương sai trích phải lớn hơn 0,5 (Hair và cộng sự, 1998) [13].

\section{KẾT QUẢ NGHIÊN CÚ̉U}

\subsection{Kết quả kiểm định thang đo}

Kết quả kiểm định độ tin cậy cho thấy, hệ số Cronbach's Alpha của các thang đo đều có giá trị lớn hơn 0,7 (thấp nhất là thang đo khả năng đáp ứng của quá trình hậu cần với $\alpha=0,888$ ). Hệ số tương quan biến tổng đều lớn hơn 0,3 . Trong đó biến $\mathrm{QT}_{6}$ có hệ số $\alpha$ của riêng bằng 0,925 lớn hơn hệ số Cronbach's Alpha chung $(0,888)$, nếu loại biến này thì hệ số Cronbach's Alpha chung sẽ tăng lên. Tuy nhiên, biến $\mathrm{QT}_{6}$ có hệ số tương quan biến tổng là $0,314>0,3$; nên có thể giữ lại biến này (chi tiết theo Bảng 4.1). Bên cạnh đó, các thang đo này có hệ số Cronbach's Alpha khá lớn và có 3 thang đo có giá trị $\alpha$ lớn hơn 0,9 là do đây là nghiên cứu lặp lại dựa trên kế thừa các nghiên cứu của Vokurka, Zank và Lund (2002); Somuyiwa và Adebayo, Toyin (2012). Vì vậy, tất cả các thang đo đều được chấp nhận và đưa vào phân tích nhân tố khám phá tiếp theo.

\subsection{Phân tích nhân tố khám phá (EFA - Exploratory Factor Analysis)}

Phần 1 , phân tích cho 4 yếu tố tạo ra khả năng đáp ứng của chuỗi cung ứng ảnh hưởng đến NLCT gồm có 21 biến quan sát. Kết quả phân tích nhân tố lần 1 không đạt yêu cầu vì biến quan sát $\mathrm{QT}_{6}=0,377$ nhỏ hơn 0,5 nên biến này sẽ bị loại. Kết quả phân tích lần 2 cho thấy, các biến được trích thành 4 nhóm, với tổng phương sai trích (hay tổng biến thiên được giải thích) bằng $73,54 \%>50 \%$; hệ số $\mathrm{KMO}=0,904$ nằm trong khoảng $0,5 \leq \mathrm{KMO} \leq 1$; vì vậy, phân tích nhân tố (EFA) là thích hợp. Kiểm định Bartlett với Sig. $=.000$, thể hiện mức ý nghĩa cao. Tất cả giá trị Factor loading của các biến quan sát đều lớn hơn 0,5 ; chênh lệch trọng số $\lambda_{\mathrm{i}} \mathrm{A}-\lambda_{\mathrm{i}} \mathrm{B}$ đều lớn hơn 0,3 nên được chấp nhận. 
Bảng 4.1: Kết quả kiểm định thang đo

\begin{tabular}{|c|c|c|c|c|}
\hline $\begin{array}{l}\text { Biến quan } \\
\text { sát }\end{array}$ & $\begin{array}{l}\text { Trung bình thang đo } \\
\text { nếu loại biến }\end{array}$ & $\begin{array}{l}\text { Phương sai thang đo } \\
\text { nếu loại biến }\end{array}$ & $\begin{array}{l}\text { Tương quan biến } \\
\text { tổng }\end{array}$ & $\begin{array}{l}\text { Cronbach's Alpha } \\
\text { nếu loại biến }\end{array}$ \\
\hline \multicolumn{5}{|c|}{ Khả năng đáp ứng của hệ thống vận hành $(\mathrm{HT})$ : Hệ số Cronbach's Alpha $=0,907$} \\
\hline $\mathrm{HT}_{1}$ & 14,90 & 10,681 & 0,798 & 0,880 \\
\hline $\mathrm{HT}_{2}$ & 14,92 & 10,821 & 0,759 & 0,888 \\
\hline $\mathrm{HT}_{3}$ & 14,87 & 10,656 & 0,721 & 0,898 \\
\hline $\mathrm{HT}_{4}$ & 14,83 & 11,209 & 0,736 & 0,893 \\
\hline $\mathrm{HT}_{5}$ & 14,90 & 10,509 & 0,825 & 0,874 \\
\hline \multicolumn{5}{|c|}{ Khả năng đáp ứng của quá trình hậu cần $(\mathrm{QT})$ : Hệ số Cronbach's Alpha $=0,888$} \\
\hline $\mathrm{QT}_{1}$ & 18,43 & 15,405 & 0,775 & 0,857 \\
\hline $\mathrm{QT}_{2}$ & 18,48 & 15,522 & 0,804 & 0,852 \\
\hline $\mathrm{QT}_{3}$ & 18,47 & 15,456 & 0,778 & 0,856 \\
\hline $\mathrm{QT}_{4}$ & 18,40 & 15,839 & 0,760 & 0,860 \\
\hline $\mathrm{QT}_{5}$ & 18,43 & 15,424 & 0,827 & 0,849 \\
\hline $\mathrm{QT}_{6}$ & 18,59 & 19,150 & 0,314 & 0,925 \\
\hline \multicolumn{5}{|c|}{ Khả năng đáp ứng của mạng lưới các nhà cung cấp $(\mathrm{ML})$ : Hệ số Cronbach’s Alpha =0,906 } \\
\hline ML1 & 14,19 & 12,295 & 0,758 & 0,887 \\
\hline ML2 & 14,29 & 12,860 & 0,745 & 0,890 \\
\hline ML3 & 14,26 & 12,593 & 0,753 & 0,888 \\
\hline ML4 & 14,26 & 12,801 & 0,741 & 0,890 \\
\hline ML5 & 14,22 & 12,314 & 0,827 & 0,872 \\
\hline \multicolumn{5}{|c|}{ Khả năng cộng tác với nhà cung cấp chiến lược $(\mathrm{CT})$ : Hệ số Cronbach’s Alpha $=0,889$} \\
\hline $\mathrm{CT}_{1}$ & 14,71 & 9,664 & 0,738 & 0,864 \\
\hline $\mathrm{CT}_{2}$ & 14,61 & 10,023 & 0,717 & 0,868 \\
\hline $\mathrm{CT}_{3}$ & 14,71 & 10,262 & 0,703 & 0,871 \\
\hline $\mathrm{CT}_{4}$ & 14,65 & 9,407 & 0,750 & 0,861 \\
\hline $\mathrm{CT}_{5}$ & 14,66 & 9,909 & 0,748 & 0,862 \\
\hline \multicolumn{5}{|c|}{$\begin{array}{l}\text { Năng lực cạnh tranh của doanh nghiệp sản xuất công nghiệp tỉnh Bà Rịa Vũng Tàu (NLCT): Hệ số Cronbach's } \\
\text { Alpha }=0,908\end{array}$} \\
\hline $\mathrm{NLCT}_{1}$ & 11,29 & 7,272 & 0,794 & 0,881 \\
\hline $\mathrm{NLCT}_{2}$ & 11,38 & 7,600 & 0,800 & 0,879 \\
\hline $\mathrm{NLCT}_{3}$ & 11,30 & 7,399 & 0,780 & 0,886 \\
\hline $\mathrm{NLCT}_{4}$ & 11,34 & 7,721 & 0,799 & 0,879 \\
\hline
\end{tabular}


Bảng 4.2: Kết quả xoay nhân tố các yếu tố tạo ra khả năng đáp ứng của chuỗi cung ứng

\begin{tabular}{|c|c|c|c|c|}
\hline \multirow[t]{2}{*}{ Mã hóa } & \multicolumn{4}{|c|}{ Nhân tố } \\
\hline & 1 & 2 & 3 & 4 \\
\hline $\mathrm{QT}_{3}$ & 0,908 & & & \\
\hline $\mathrm{QT}_{5}$ & 0,898 & & & \\
\hline $\mathrm{QT}_{4}$ & 0,862 & & & \\
\hline $\mathrm{QT}_{1}$ & 0,859 & & & \\
\hline $\mathrm{QT}_{2}$ & 0,847 & & & \\
\hline $\mathrm{ML}_{5}$ & & 0,904 & & \\
\hline $\mathrm{ML}_{1}$ & & 0,855 & & \\
\hline $\mathrm{ML}_{4}$ & & 0,847 & & \\
\hline $\mathrm{ML}_{3}$ & & 0,844 & & \\
\hline $\mathrm{ML}_{2}$ & & 0,803 & & \\
\hline $\mathrm{HT}_{5}$ & & & 0,922 & \\
\hline $\mathrm{HT}_{1}$ & & & 0,872 & \\
\hline $\mathrm{HT}_{4}$ & & & 0,848 & \\
\hline $\mathrm{HT}_{3}$ & & & 0,828 & \\
\hline $\mathrm{HT}_{2}$ & & & 0,770 & \\
\hline $\mathrm{CT}_{4}$ & & & & 0,851 \\
\hline $\mathrm{CT}_{1}$ & & & & 0,844 \\
\hline $\mathrm{CT}_{5}$ & & & & 0,832 \\
\hline $\mathrm{CT}_{2}$ & & & & 0,822 \\
\hline $\mathrm{CT}_{3}$ & & & & 0,800 \\
\hline Eigenvalue & 7,832 & 2,666 & 2,496 & 1,715 \\
\hline$\%$ of Variance & 39,158 & 13,329 & 12,478 & 8,575 \\
\hline KMO & & & & 0,904 \\
\hline & Chi-Square & & & 2929,673 \\
\hline Bartlett's Test & df & & & 190 \\
\hline & Sig. & & &, 000 \\
\hline
\end{tabular}

Nguồn: Kết quả phân tích EFA của tác giả

Phần 2, phân tích cho NLCT của doanh nghiệp sản xuất công nghiệp tỉnh Bà Rịa Vũng Tàu gồm có 4 biến quan sát. Kết quả phân tích nhân tố cho thây, tổng phương sai trích $=78,53 \%>50 \%$, thang đo được chấp nhận. Hệ số $\mathrm{KMO}=0,835$ nằm trong khoảng $0,5 \leq \mathrm{KMO} \leq 1$, phân tích nhân tố là thích hợp. Kiểm định Bartlett với Sig. $=.000$, thể hiện mức ý nghĩa cao. Giá trị Factor loading của tất cả các biên quan sát nhóm này đều lớn hơn 0.5 và được chấp nhận.

Bảng 4.3: Kết quả xoay nhân tố NLCT của doanh nghiệp sản xuất công nghiệp tỉnh Bà Rịa Vũng Tàu

\begin{tabular}{|c|c|c|c|}
\hline \multirow{2}{*}{ Mã hóa } & & \multicolumn{2}{|l|}{ Factor } \\
\hline & & 1 & \\
\hline $\mathrm{NLCT}_{2}$ & & 0,892 & \\
\hline $\mathrm{NLCT}_{4}$ & & 0,891 & \\
\hline $\mathrm{NLCT}_{1}$ & & 0,886 & \\
\hline $\mathrm{NLCT}_{3}$ & & 0,876 & \\
\hline Eigenvalue & & 3,141 & \\
\hline$\%$ of Variance & & 78,531 & \\
\hline $\mathrm{KMO}$ & & & 0,835 \\
\hline Bartlett's Test & Chi-Square & & 563,384 \\
\hline & $\mathrm{df}$ & & 6 \\
\hline & Sig. & & ,000 \\
\hline
\end{tabular}

Nguồn: Kết quả phân tích EFA của tác giả 


\subsection{Phân tích nhân tố khẳng định CFA}

Độ tin cậy tổng hợp và phương sai trích của thang đo các yếu tố tạo ra khả năng đáp ứng của chuỗi cung ứng ảnh hưởng đển NLCT của doanh nghiệp, nghiên cứu trường hợp các doanh nghiệp sản xuất công nghiệp tỉnh Bà Rịa Vũng Tàu cho thấy đảm bảo đạt yêu cầu về giá trị (chi tiết theo Bảng 4.4).

Bảng 4.4: Kết quả phân tích CFA

\begin{tabular}{|c|c|c|c|c|c|}
\hline \multirow[b]{2}{*}{ Khái niệm } & \multirow[b]{2}{*}{ Thang đo } & \multirow{2}{*}{$\begin{array}{l}\text { Số biến } \\
\text { quan sát }\end{array}$} & \multicolumn{2}{|c|}{ Độ tin cậy } & \multirow[b]{2}{*}{$\begin{array}{l}\text { Phương } \\
\text { sai trích }\end{array}$} \\
\hline & & & Cronbach & $\begin{array}{l}\text { Tổng } \\
\text { hợp }\end{array}$ & \\
\hline Các yếu tố & Khả năng đáp ứng của hệ thống vận hành (HT) & 5 & 0,907 & 0,909 & 0,667 \\
\hline tố tạo ra khả & Khả năng đáp ứng của quá trình hậu cần $(\mathrm{QT})$ & 5 & 0,888 & 0,926 & 0,713 \\
\hline $\begin{array}{l}\text { năng đáp } \\
\text { ứng của }\end{array}$ & $\begin{array}{l}\text { Khả năng đáp ứng của mạng lưới các nhà cung cấp } \\
\text { (ML) }\end{array}$ & 5 & 0,906 & 0,907 & 0,661 \\
\hline $\begin{array}{c}\text { chuỗi cung } \\
\text { ứng }\end{array}$ & $\begin{array}{l}\text { Khả năng cộng tác với nhà cung cấp chiến lược } \\
\text { (CT) }\end{array}$ & 5 & 0,889 & 0,890 & 0,618 \\
\hline \multicolumn{2}{|c|}{$\begin{array}{l}\text { Năng lực cạnh tranh của doanh nghiệp sản xuất công nghiệp tỉnh Bà } \\
\text { Rịa Vưng Tàu (NLCT) }\end{array}$} & 4 & 0,908 & 0,909 & 0,714 \\
\hline
\end{tabular}

Nguồn: Kết quả phân tích CFA của tác giả

Kết quả CFA của mô hình đo lường sau cùng (mô hình tới hạn) cho thấy, mô hình là phù hợp với dữ liệu, chi bình phương $=326,642 ;$ có bậc tự do $=242$, giá trị $\mathrm{P}=0.000 ; \mathrm{CMIN} / \mathrm{df}=1,350<2$. Các chỉ tiêu đo lường $\mathrm{GFI}=0,896 ; \mathrm{TLI}=0,974 ; \mathrm{CFI}=0,977$ đều lớn hơn 0,$8 ; \mathrm{RMSEA}=0,040<0,08$ dều đạt yêu cầu (chi tiết theo Hinh 4.1).

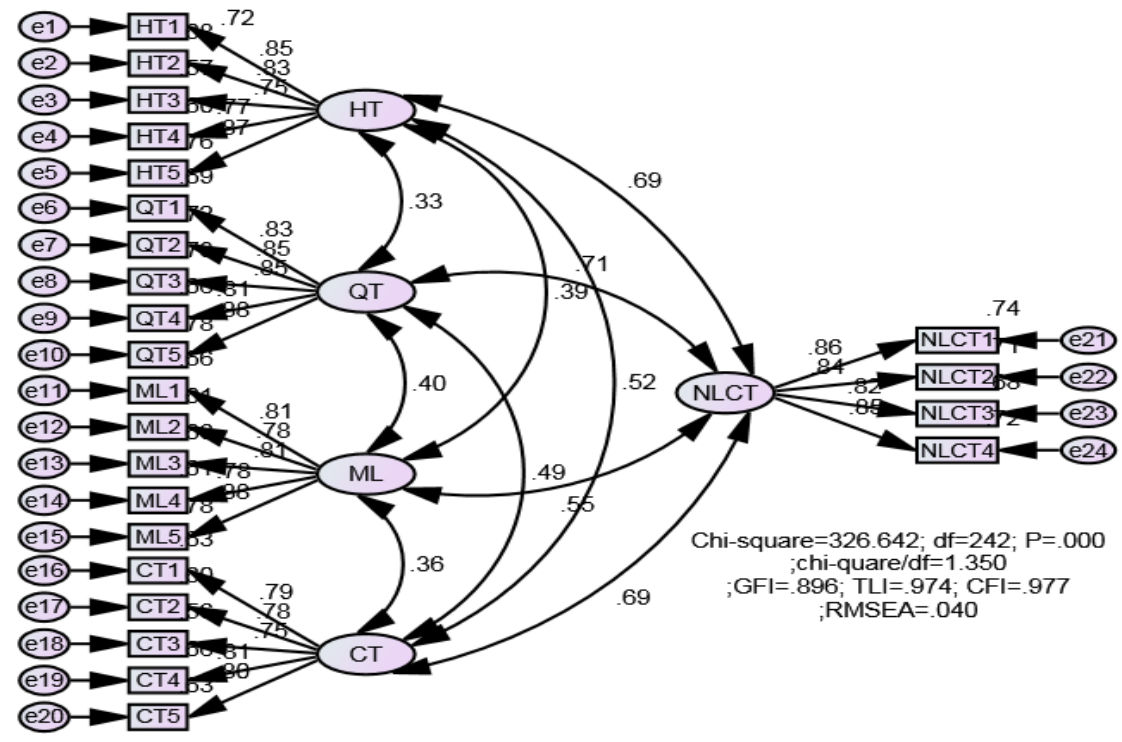

Hình 4.1 Kết quả CFA của mô hình tới hạn

Như vậy, kết quả CFA cho mô hình đo lường sau cùng cho thấy, các yếu tố trong mô hình đều đạt tính đơn hướng, đảm bảo giá trị hội tụ, đảm bảo độ tin cậy và giá trị phân biệt. Mô hình nghiên cứu là phù hợp với dữ liệu thị trường.

\subsection{Phân tích mô hình cấu trúc tuyến tính SEM (Structural Equation Modeling)}

\subsubsection{Kiểm định mô hình nghiên cứu và các giả thuyết}

Kết quả ước lượng (chuẩn hóa) mô hình nghiên cứu cho thấy, mô hình là phù hợp với dữ liệu, chi bình phương $=479,058$; có bậc tự do $=248$, giá trị $\mathrm{P}=, 000 ; \mathrm{CMIN} / \mathrm{df}=1,932<2$. Các chỉ tiêu đo lường $\mathrm{GFI}=0,843 ; \mathrm{TLI}=0,930 ; \mathrm{CFI}=0,937$ dều lớn hơn 0,$8 ; \mathrm{RMSEA}=0,066<0,08$ đều đạt yêu cầu $($ chi tiểt theo Hinh 4.2). 


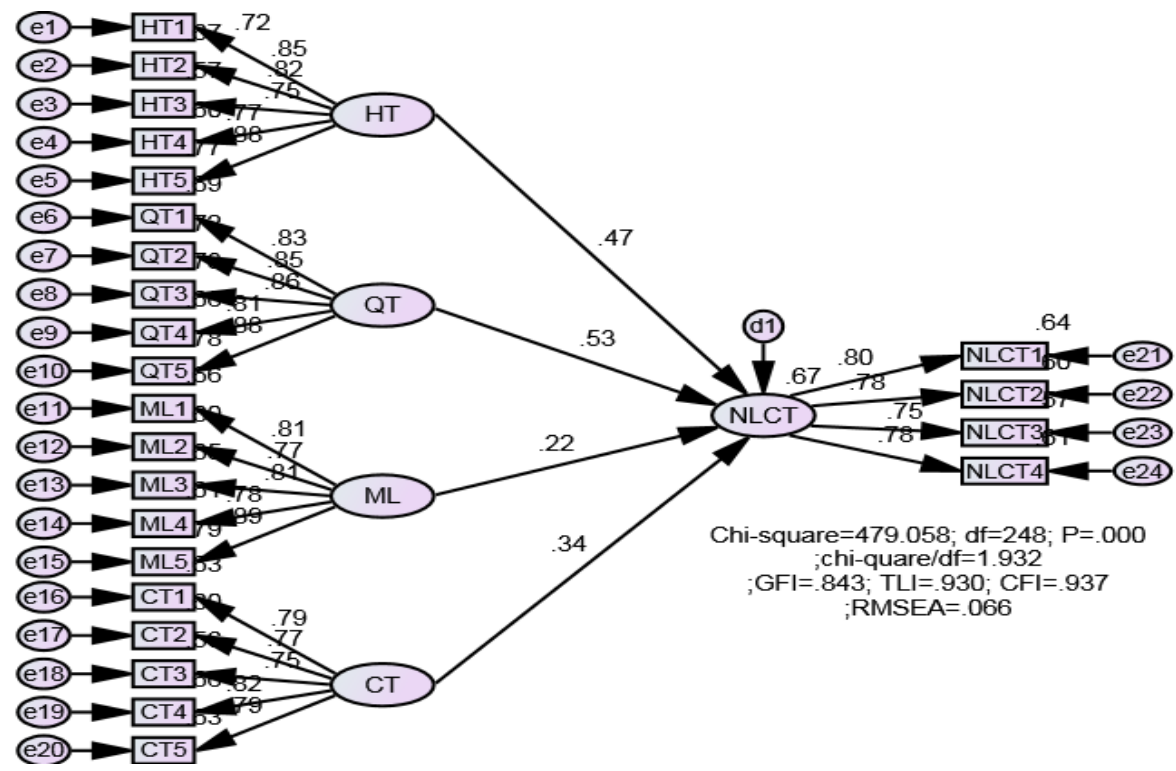

Hình 4.2 Kết quả SEM (chuẩn hóa) của mô hình nghiên cứu

\subsubsection{Kiểm định ước lượng mô hình nghiên cứu bằng Bootstrap}

Kết quả ước lượng với $\mathrm{N}=500$ được tính trung bình kèm theo, cho thấy độ chệch (bias) tuy có xuất hiện nhưng rất nhỏ. Vì vậy, có thể kết luận là các ước lượng trong mô hình có thể tin cậy được.

\subsubsection{Kiểm định các giả thuyết nghiên cứu bằng mô hình cấu trúc tuyến tính SEM}

Kết quả ước lượng mô hình nghiên cứu và bootstrap trong phân tích mô hình cấu trúc tuyến tính (SEM) cho thấy, mối quan hệ được giả thuyết trong mô hình nghiên cứu có ý nghĩa thống kê vì các giá trị $\mathrm{p}$ đều nhỏ hơn 0,05; đạt mức ý nghĩa cần thiết ở độ tin cậy $95 \%$ (chi tiết theo Bảng 4.5).

Bảng 4.5: Bảng hệ số hồi quy của mô hình nghiên cứu

\begin{tabular}{|c|c|c|c|c|c|c|c|c|}
\hline \multicolumn{3}{|c|}{ Quan hệ } & Hệ số & Hệ số (chuẩn hóa) & S.E. & C.R. & $\mathbf{P}$ & Kết luận giả thuyết \\
\hline NLCT & $<---$ & HT & 0,408 & 0,471 & 0,052 & 7,869 & $* * *$ & Chấp nhận $\mathrm{H}_{1}$ \\
\hline NLCT & $<---$ & CT & 0,339 & 0,337 & 0,059 & 5,735 & $* * *$ & Chấp nhận $\mathrm{H}_{4}$ \\
\hline NLCT & $<---$ & ML & 0,181 & 0,225 & 0,044 & 4,114 & $* * *$ & Chấp nhận $\mathrm{H}_{3}$ \\
\hline NLCT & $<--$ & QT & 0,444 & 0,530 & 0,051 & 8,675 & $* * *$ & Chấp nhận $\mathrm{H}_{2}$ \\
\hline
\end{tabular}

Nguồn: Kết quả nghiên cứu của tác giả

Vì các giá trị $\mathrm{p}$ đều nhỏ hơn $0,05(* * *)$ nên các giả thuyết trong mô hình nghiên cứu chính thức từ $\mathrm{H}_{1}$ cho đến $\mathrm{H}_{4}$ đều được chấp nhận. Điều này có nghĩa là NLCT của các doanh nghiệp sản xuất công nghiệp tỉnh Bà Rịa Vũng Tàu bị ảnh hưởng cùng chiều bởi 4 yếu tố tạo ra khả năng đáp ứng của chuỗi cung ứng.

\section{THẢO LUẪN KẾT QUẢ NGHIÊN CỨU VÀ HÀM Ý QUẢN TRI}

\subsection{Thảo luận kết quả nghiên cứu}

Kết quả nghiên cứu cho thấy, có 4 yếu tố tạo ra khả năng đáp ứng của chuỗi cung ứng có ảnh hưởng cùng chiều đến NLCT của doanh nghiệp sản xuất công nghiệp tỉnh Bà Rịa Vũng Tàu. Mức độ quan trọng của từng yếu tố này đến NLCT của doanh nghiệp là khác nhau, cụ thể: Thứ nhất, khả năng đáp ứng của quá trình hậu cần (Giả thuyết $\mathrm{H}_{2}$ ) với hệ số bằng 0,530 ; Thư hai, khả năng đáp ứng của hệ thống vận hành (Giả thuyết $\mathrm{H}_{1}$ ) với hệ số bằng 0,471 ; Thư $b a$, khả năng cộng tác với nhà cung cấp chiến lược (Giả thuyết $\mathrm{H}_{4}$ ) với hệ số bằng 0,337 ; Thư $t u$, khả năng đáp ứng của mạng lưới các nhà cung cấp (Giả thuyết $\left.\mathrm{H}_{3}\right)$ với hệ số bằng 0,225 . Theo kết quả nghiên cứu, khả năng đáp ứng của chuỗi cung ứng có ảnh hưởng tích cực đến NLCT của doanh nghiệp sản xuất công nghiệp tỉnh Bà Rịa Vũng Tàu là hoàn toàn phù hợp với lý 
thuyết và nghiên cứu thực nghiệm của Somuyiwa và Adebayo, Toyin (2012). Tuy nhiên, nghiên cứu của Somuyiwa và Adebayo, Toyin (2012) [24] cho rằng khả năng cạnh tranh của doanh nghiệp bị ảnh hưởng bởi khả năng đáp ứng và vận hành của chuỗi cung ứng trong mối quan hệ gián tiếp. Còn trong nghiên cứu này, tác giả cho thấy sự ảnh hưởng trực tiếp của các yếu tạo nên khả năng đáp ứng của chuỗi cung ứng đến NLCT của doanh nghiệp. Bên cạnh đó, nghiên cứu này cũng đề cập đến yếu tố quan trọng mà các nghiên cứu trước chưa đề cập là khả năng cộng tác với nhà cung cấp chiến lược nhằm đảm bảo cho sự ổn định của chuỗi cung ứng dựa vào tham khảo ý kiến chuyên gia và thảo luận nhóm.

\subsection{Các hàm ý quản trị}

- Khả năng đáp ứng của quá trình hậu cần được đánh giá là quan trọng nhất ảnh hưởng đến NLCT của doanh nghiệp sản xuất công nghiệp. Do vậy, nhà quản trị cần quan tâm đến tiến độ vận chuyển của hàng hóa, nguyên vật liệu; hệ thống thông tin về hàng hóa, nguyên vật liệu trong kho phải đáng tin cậy và đúng lúc; sự phối hợp nhịp nhàng, linh hoạt giữa doanh nghiệp và nhà cung cấp; hệ thống kho bãi của doanh nghiệp đảm bảo yêu cầu phục vụ tốt cho hệ thống vận hành; các hoạt động xuất, nhập nguyên vật liệu của hệ thống kho phải nhanh gọn và đơn giản.

- Khả năng đáp ứng của hệ thống vận hành được đánh giá là quan trọng thứ hai ảnh hưởng đến NLCT của doanh nghiệp sản xuất công nghiệp. Do vậy, nhà quản trị cần chú trọng đến sự linh hoạt trong mỗi giai đoạn của quá trình sản xuất. Cần đảm bảo chất lượng sản phẩm trong từng giai đoạn của hệ thống vận hành, sản phẩm đang sản xuất dở dang của giai đoạn trước phải là đầu vào đáng tin cậy cho giai đoạn sau. Cần có hệ thống giám sát kỹ thuật cho từng giai đoạn, không để sản phẩm kém chất lượng xuất xưởng ra thị trường nhằm tạo niềm tin với khách hàng.

- Đối với doanh nghiệp sản xuất công nghiệp, nhà cung cấp tốt thật sự là một tài nguyên vô giá, bởi chính nhà cung ứng sẽ góp phần trực tiếp vào thành công của doanh nghiệp. Nhà cung cấp tốt không chỉ giao hàng đúng chất lượng, đủ số lượng, kịp thời gian, với giá cả hợp lý,... mà còn hỗ trợ khách hàng phát triển sản phẩm, phân tích giá trị, sẵn sàng hợp tác trong các chương trình tiết kiệm chi phí,... giúp người mua đạt được hiệu quả cao hơn. Vì vậy, xây dựng mối quan hệ lâu dài và bền vững với nhà cung cấp chiến lược được xem là yếu tố quan trọng ảnh hưởng đến NLCT doanh nghiệp sản xuất công nghiệp. Nhà quản trị cần xây dựng chiến lược mở rộng và phát triển nhà cung cấp tiềm năng; xem nhà cung cấp là đối tác chiến lược cho sự phát triển; xem mối quan hệ giữa doanh nghiệp và nhà cung cấp là quan hệ bình đẳng, cùng có lợi. Nhà quản trị cần xây dựng văn hóa giao tiếp và quán triệt đến nhân viên của mình không nên có sự phân biệt đối xử giữa nhà cung cấp và khách hàng.

- Nhà cung cấp có thể chi phối các hoạt động của doanh nghiệp nếu họ có sự thống trị hoặc khả năng độc quyền. Họ luôn đe dọa tới nhà sản xuất do tầm quan trọng của nguyên vật liệu cung cấp, do đặc tính khác biệt hoá cao độ của người cung cấp với người sản xuất, do sự thay đổi về giá cả nguyên vật liệu cung cấp hoặc do sự liên kết giữa những người cung cấp gây ra... Do đó, khả năng đáp ứng của mạng lưới các nhà cung cấp được đánh giá là rất quan trọng ảnh hưởng đến NLCT doanh nghiệp sản xuất công nghiệp. Trong trường hợp này, nhà quản trị cần quan tâm đến năng lực tài chính của các nhà cung cấp; hệ thống phân phối, giao hàng của nhà cung cấp. Ngoài mạng lưới nhà cung cấp hiện tại, nhà quản trị trong doanh nghiệp cần có chiến lược mở rộng và phát triển mạng lưới nhà cung cấp tiềm năng. Bên cạnh đó, định kỳ hàng quí, hàng năm doanh nghiệp cần tổ chức đánh giá lại năng lực của nhà cung cấp để có sự lựa chọn phù hợp hơn.

\section{HẠN CHẾ VÀ HƯớNG NGHIÊN CÚU TIẾP THEO}

Nghiên cứu các yếu tố tạo ra khả năng đáp ứng của chuỗi cung ứng ảnh hưởng đến NLCT của doanh nghiệp phát triển theo hướng các giả thuyết nghiên cứu được kiểm định cho trường hợp tỉnh Bà Rịa Vũng Tàu và trong ngành sản xuất công nghiệp. Tuy nhiên, doanh nghiệp sản xuất công nghiệp tại Bà Rịa Vũng Tàu còn hạn chế về số lượng và qui mô. Do đó, kết quả nghiên cứu chỉ mang tính đặc thù cho tỉnh Bà Rịa Vũng Tàu, chưa mang tính đại diện cho các địa phương khác trong cả nước. Từ hạn chế trên, nghiên cứu tiếp theo không chỉ dừng lại ở các yếu tố tạo ra khả năng đáp ứng của chuỗi cung ứng ảnh hưởng đến NLCT của doanh nghiệp tại Bà Rịa Vũng Tàu mà còn mở rộng ra các lĩnh vực kinh doanh khác, địa phương khác. 
CẠNH TRANH DOANH NGHIỆP, NGHIÊN CÚUU TRƯÒ̀NG HỢP TẠI TİNH BÀ RỊA VŨ்NG TÀU

\section{TÀI LIỆU THAM KHẢO}

[1] Aldington Report. (1985), Report from the Select Committee of the House of Lords on Overseas Trade, London: HMSO.

[2] Aquilano, N. J., Chase, R. B., \& Davis, M. M. (1995), Fundamentals of operations management, Chicago, IL: Irwin.

[3] Barclay, L. A. (2005), The Competitiveness of Trinidad and Tobago and Manufacturing Firms in an Increasingly Liberalised Trading Environment, Journal of Eastern Caribbean Studies, 30, (2): 41-74.

[4] Bowersox, D. J., Closs, D. J., \& Stank, T. P. (1999), 21st Century logistics: Making supply chain integration a reality, The Council of Logistics Management, Oak Brook, IL.

[5] Carmines, E. \& McIver, J. (1981), Analyzing models with unobserved variables: analusis of covariance tructures, Beverly Hills, CA: Sage Publications 65/115.

[6] Christopher, M., \& Peck, H. (2004), Building the resilient supply chain, International Journal of Logistics Management, 15(2), 1-13.

[7] D’Cruz, J \& Rugman, A. (1992), New Concepts for Canadian Competitiveness, Kodak, Canada.

[8] D'Hauteserre, A. M. (2000), Lessons in managed destination competitiveness: the case of Foxwoods casino resort, Tourism Management, 21, 23-32.

[9] Duclos, L. K., Vokurka, R. J., \& Lummus, R. R. (2003), A conceptual model of supply Chain Flexibility, Industrial Management \& Data Systems, 103(6), 446-456.

[10] Dunning, J. H. (1993), Multinational Enterprises and the Global Economy. Wokingham, England: Addison Wesley Publishing Company.

[11] Fawcett, S. E. (1992), Strategic logistics in coordinated global manufacturing success, International Journal of Production Research, 30(5), 1081-2000.

[12] Hair J.F, Anderson, R.E., Tatham, R.L., and Black, W.C. (2006), Multivariate data analysis, Prentice-Hall, International, Inc.

[13] Hair J.F, Anderson,R.E., Tatham, R.L., \& Black, W.C. (1998), Multivariate data analysis with readings, 5th ed, Prentice-Hall, New Jersey.

[14] Hassan, S. (2000), Determinants of Market Competitiveness in an Environmentally Sustainable Tourism Industry, Journal of Travel Research, 38(3), 239-245.

[15] Holweg, M. (2005), An investigation into supplier responsiveness, International Journal of Logistics Management, 16(1), 96-119.

[16] Horstmann, I., \& Markusen, J. R. (1992), Endogenous Market Structures in International Trade, Journal of International Economics, 32, 109-129.

[17] Li, S., Ragu-Nathan, B., Ragu-Nathan, T. S., \& Rao, S. S. (2006), The impact of supply chain management practices on competitive advantage and organizational performance, Omega, 34(2), 107-124.

[18] Li, V. (2011), The methodology to assess the competitiveness of real estate developers in China, Queensland University of Technology.

[19] Nguyễn Bách Khoa (2004), Phương pháp xác định năng lực cạnh tranh và hội nhập kinh tế quốc tế của doanh nghiệp, Tạp chi khoa học thương mại, số 4,5, Hà Nội. 

CẠNH TRANH DOANH NGHIẸP, NGHIÊN CÚU TRUOÒNG HỘP TẠI TỈNH BÀ RỊA VŨ்NG TÀU

[20] Nguyễn Đình Thọ (2011), Phuoong pháp nghiên cưu khoa học trong kinh doanh, Nhà xuất bản Lao động Xã hội, Hà Nội.

[21] Nunnally, JC. \& Bernstein, I.H. (1994), Psychometric Theory (3 nd), New York: Me Graw-Hill.

[22] Porter, M. E. (1980), Competition strategy-Techniques for Analyzing Industries and Competitors, New York: The Free Press.

[23] Porter, M. E. (1985), Competitive Advantage: Creating and Sustaining. Superior Performance, Free Press, NY.

[24] Somuyiwa, A. O., \& Adebayo, Toyin, I. (2012), Firm's Competitiveness through Supply Chain Responsiveness and Supply Chain Management Practices in Nigeria. British Journal of Arts and Social Sciences, 10(I), pp 2046-9578.

[25] Steenkamp, J.B.E.M., \& Van Trijp, H.C.M. (1991), The use of LISREL in validating marketing constructs, International Journal of Research in Marketing, 8(4), pp 283-299.

[26] Stuart, F. I. (1993), Supplier partnerships: Influencing factors and strategic benefits, International Journal of Purchasing and Materials Management, Fall, 22-28.

[27] Tan, K. C., Lyman, S. B., \& Wisner, J. D. (2002), Supply chain management: A strategic perspective, International Journal of Operations and Production Management, 22(6), pp 614-631.

[28] Vokurka, R. J., Zank, G. M., \& Lund, C. M. (2002), Improving competitiveness through supply chain management: a cumulative improvement approach, Competitiveness Review, 12(1), 14-25.

[29] Walker, W. T. (2005), Supply chain flexibility, ASCET Supply Chain, White Paper.

[30] Williams, D. A. (2007), Competitiveness of Small Enterprises: Insights from a Developing Economy, The Round Table, 96(390), 347-363.

[31] Wint, A. G. (2003), Competitiveness in Small Developing Economies: Insights from the Caribbean, Kingston: The University of the West Indies Press.

Ngày nhận bài: 07/06/2017

Ngày chấp nhận đăng: 10/10/2017 